\title{
Trends and variability in atmospheric precipitable water over the Tibetan Plateau for 2000-2010
}

\author{
Ning Lu, ${ }^{a *}$ Jun Qin, ${ }^{\mathrm{b}}$ Yang Gao, ${ }^{\mathrm{b}}$ Kun Yang, ${ }^{\mathrm{b}}$ Kevin E. Trenberth, ${ }^{\mathrm{c}}$ Maria Gehne ${ }^{\mathrm{c}}$ and \\ Yunqiang $\mathrm{Zhu}^{\mathrm{a}}$ \\ a State Key Laboratory of Resources and Environmental Information System, Institute of Geographic Sciences and Natural Resources Research, \\ Chinese Academy of Sciences, Beijing, China \\ ${ }^{\mathrm{b}}$ Key Laboratory of Tibetan Environment Changes and Land Surface Processes, Institute of Tibetan Plateau Research, Chinese Academy of \\ Sciences, Beijing, China \\ ${ }^{c}$ National Center for Atmospheric Research, Boulder, CO, USA
}

\begin{abstract}
The trends and variations in precipitable water (PW) over the Tibetan Plateau (TP) from 2000 to 2010 are analysed using the monthly mean PW datasets from Moderate Resolution Imaging Spectroradiometer (MODIS) and ERA-Interim reanalysis of European Centre for Medium-Range Weather Forecasts (ECMWF). Three different methods (including linear fit, non-parametric and non-linear) are used to estimate PW trends and their significance. The trend patterns derived from MODIS and ECMWF are very similar except for the magnitude. Increasing trends are found in the eastern and western TP; with decreasing trends in the middle. Atmospheric water vapour is more changeable compared to the surrounding areas and large PW anomalies occur frequently in July and August over the TP. Regression analysis between monthly mean anomalies of ECMWF PW and ECMWF surface air temperature (SAT) indicates reanalyses data show larger regression slope $\left(7.36 \pm 0.75 \% \mathrm{~K}^{-1}\right)$ over the TP than the MODIS observations $\left(4.81 \pm 0.72 \% \mathrm{~K}^{-1}\right)$ mainly in the non-monsoon season. The comparison of the vertically integrated moisture flux and its divergence between the wettest and driest monsoon seasons indicates that the PW spatial variability in monsoon seasons over the TP is affected by the large-scale atmospheric circulation. Although the TP region is under the influence of one large-scale circulation pattern (the monsoon) and the consistent warming background, the PW trends and the relation of PW and temperature are spatially heterogeneous, which is particularly important for predicting hydrological changes in this region.
\end{abstract}

KEY WORDS precipitable water; MODIS; Tibetan Plateau; trend and variability

Received 9 August 2013; Revised 4 May 2014; Accepted 7 May 2014

\section{Introduction}

Atmospheric water vapour plays an important role in energy budget and hydrological processes on both local and global scales (Trenberth et al., 2005). It not only represents the movement of energy in the form of latent heat (released by condensation), but also is the important greenhouse gas with almost double heat-amplifying effect than carbon dioxide in the atmosphere (Dessler et al., 2008). Precipitable water (PW), the column-integrated atmospheric water vapour, is regarded as a proxy for the climate state of a region (Mieruch et al., 2008), and thus the trends of PW denote the regional changes whether a region is getting more humid or drier.

The Tibetan Plateau (TP), with an area of approximately $2.4 \times 10^{6} \mathrm{~km}^{2}$, is the most extensive highland in the world. The air mass in this region is only about half of that at sea level and the aerosol load is low. Water vapour over the

\footnotetext{
* Correspondence to: N. Lu, State Key Laboratory of Resources and Environmental Information System, Institute of Geographic Sciences and Natural Resources Research, Chinese Academy of Sciences, Beijing, China. E-mail: ning.robin@gmail.com
}

TP influences the downward solar radiation (Yang et al., 2012), facilitates the development of convective clouds under strong solar heating at the surface (Yang et al., 2004) and has a great impact on the downstream floods and droughts (Xu et al., 2008b).

TP exerts influence on the migration and temporal variability of the Asian monsoon through thermal and mechanical effects (Yanai and $\mathrm{Wu}, 2006$ ) and experiences altitude-dependent warming (Qin et al., 2009). The thermal forcing of TP plays a dominant role in the generation of the Asian summer monsoon (Wu et al., 2012), through elevated surface sensible heating (Tang et al., 2013) and thermal insulation (Boos and Kuang, 2010). Meanwhile, the seasonal variation in water vapour over the TP is largely controlled by the monsoon system through water vapour transport. Previous studies conclude that the routes of moisture supply to the TP originate from three sources: Bay of Bengal, the Arabian Sea and the mid-latitude westerlies (Simmonds et al., 1999; Xu et al., 2008b; Drumond et al., 2011; Chen et al., 2012). For instance, during the monsoon season over the TP (from May to September), the strong Indian monsoon brings abundant moisture evaporated from the Arabian Sea and the Bay of Bengal 
(Zhang, 2001; Chen et al., 2012). Therefore, the changing pattern of water vapour over the TP is also influenced by the evolution and variability of the monsoon system.

The global trends of PW have been investigated using satellite data of Global Ozone Monitoring Experiment (GOME) (Wagner et al., 2006) and Scanning Imaging Absorption spectroMeter for Atmospheric CHartographY (SCIAMACHY) (Mieruch et al., 2008), but these studies did not include the TP region because of data limitations. Atmospheric water vapour is highly variable in both space and time across the TP region. Due to the scarcity and uneven distribution of the ground measurements in the TP, the regional patterns of trend and variability in PW for this region remain unclear. Satellite observations and reanalysis data for the recent decade enable us to detect the patterns. Although the length of these satellite-derived PW data cannot resolve the long-term trend, it is enough to show significant water vapour changes over the TP. The Moderate Resolution Imaging Spectroradiometer (MODIS) provides spatial and temporal PW data (Gao and Kaufman, 2003), which has been validated to represent the temporal variation of PW over the TP accurately (Lu et al., 2011). The ERA-Interim reanalysis of the European Centre for Medium-Range Weather Forecasts (ECMWF) also provides PW data (Dee et al., 2011), covering the same period as the MODIS data. Therefore, the spatial patterns of trend and temporal variability in PW over the TP can be derived from the MODIS and ECMWF data. Moreover, comparison between the MODIS and ECMWF data can demonstrate to which extent the physical mechanisms are well reproduced by the climate model in the reanalyses system.

Details of the observations and the analytic approach to trend estimation are provided in Section 2. Section 3 describes the observed PW variability and trends over the $\mathrm{TP}$, and discusses the effects of changes in near-surface temperature on $\mathrm{PW}$ and the influence of water vapour transport to the TP. Section 4 provides concluding remarks.

\section{Data and methods}

\subsection{Data for precipitable water and surface air} temperature

The monthly mean PW data used for the period 20002010 were derived from MODIS Collection-5 products and ECMWF reanalysis (ERA-Interim) data for the area $25^{\circ}-45^{\circ} \mathrm{N}, 65^{\circ}-105^{\circ} \mathrm{E}$ (the Himalayas and TP). The MODIS water vapour data were obtained from the Goddard Earth Sciences Distributed Active Archive Center (DAAC), and the ERA-Interim reanalysis from European Centre for Medium-Range Weather Forecasts. The spatial resolution for the MODIS Collection-5 products is $1^{\circ}$. Daily and seasonal variations of PW have been observed reliably from MODIS channels located within and around the 0.94- $\mu \mathrm{m}$ water band (Gao and Kaufman, 2003). Previous studies have shown that monthly mean PW of MODIS is able to represent the seasonal and annual water vapour variation over the TP (Lu et al., 2011).
ERA-Interim is the latest global atmospheric reanalysis produced by the ECMWF, covering the period from 1 January 1979 onwards and extending forward in near-real time (Dee et al., 2011). The horizontal resolution for the ERA-Interim products is $1.5^{\circ}$. PW of ERA-Interim is derived in part from assimilation of rain-affected radiances from passive microwave imagers (SSM/I, SSMI/S, AMSRE), using the $1 \mathrm{D}+4 \mathrm{D}$ variational analysis scheme (Dee and Uppala, 2009; Dee et al., 2011). These microwave data are assimilated over oceans in ECMWF. So the ECMWF PW over the TP is the innovative information generated by the assimilation system. Consequently, ECMWF PW data is independent of MODIS PW observations.

To demonstrate the relationship between water vapour and temperature over the TP, we will compare the PW trends to air temperature trends (in Section 3.2). The temperature data we used are 2-m air temperature data from ECMWF for the same period. When compared with ECMWF air temperature, the spatial resolution of MODIS $\left(1^{\circ}\right)$ is interpolated to the same resolution as ECMWF $\left(1.5^{\circ}\right)$.

\subsection{Trend estimation}

The trend in PW over the TP was estimated using the monthly time series data for 2000-2010. Three different estimation methods were used. The first one is enhanced linear trend fit, which considers the seasonal cycle and autocorrelation of noise in the time series. The trend analysis is based on the approach described in Weatherhead et al. (1998) and Mieruch et al. (2008). The second one is seasonal Mann-Kendall (SMK). It is a non-parametric seasonal Kendall test modified to account for serial dependence (Hirsch and Slack, 1984), for example, correlation between months, by inflating the variance of the test statistic. Since the SMK test is non-parametric, it does not make any assumptions about normality or linearity. The third method is the ensemble empirical mode decomposition (EEMD), which is a major refinement of the original empirical mode decomposition (Wu and Huang, 2009). EEMD is used to derive the adaptive, non-linear trend from a time series, providing time-varying trend change in the time series which is useful to examine the nonstationary and nonlinear processes. Note that the trend estimation was performed on monthly PW time series, but the estimated trend is annual trend in mm year ${ }^{-1}$ (relative trend in \% year ${ }^{-1}$ ) for all three methods.

\section{Results and discussion}

3.1. Precipitable water variability and trend analysis

The summer monsoon season usually spans from May to September, bringing a large amount of atmospheric water vapour from the tropical ocean to the TP. Therefore, water vapour over the TP greatly increases during this period relative to the other months. This phenomenon was also observed by the ground Global Positioning System network measurements (Lu et al., 2011). 
Therefore, we have combined the months from May, June, July, August and September as summer monsoon season months, and October, November, December, January, February, March and April as non-monsoon season months.

Figure 1(a) shows the average values of MODIS PW for the monsoon and non-monsoon months for 2000-2010, respectively. The average values of atmospheric water vapour over the TP are much smaller than those over the surrounding low-elevation regions (Gao et al., 2003), with the areal average of $10.9 \pm 5.9 \mathrm{~mm}$ (two sigma) for the monsoon season and $3.5 \pm 2.9 \mathrm{~mm}$ for the non-monsoon season. While in the surrounding low-elevation regions such as Bengal, its areal average PW is $63.2 \pm 0.7 \mathrm{~mm}$ for the monsoon season and $30.2 \pm 1.1 \mathrm{~mm}$ for the non-monsoon season. Therefore, the relative anomaly, i.e. the ratio between absolute anomaly (with PW mean value subtracted) and PW mean value over the sampling period, is more suitable to compare the PW variability of the TP to the surrounding areas. The standard deviations and their relative values of PW give the magnitude of the variability (Figure 1(b) and 1(c)). In monsoon season, large standard deviations (greater than 25\%) occur over the TP, indicating that the water vapour sometimes varies far from the mean and becomes variable compared to the non-monsoon season.

(a)

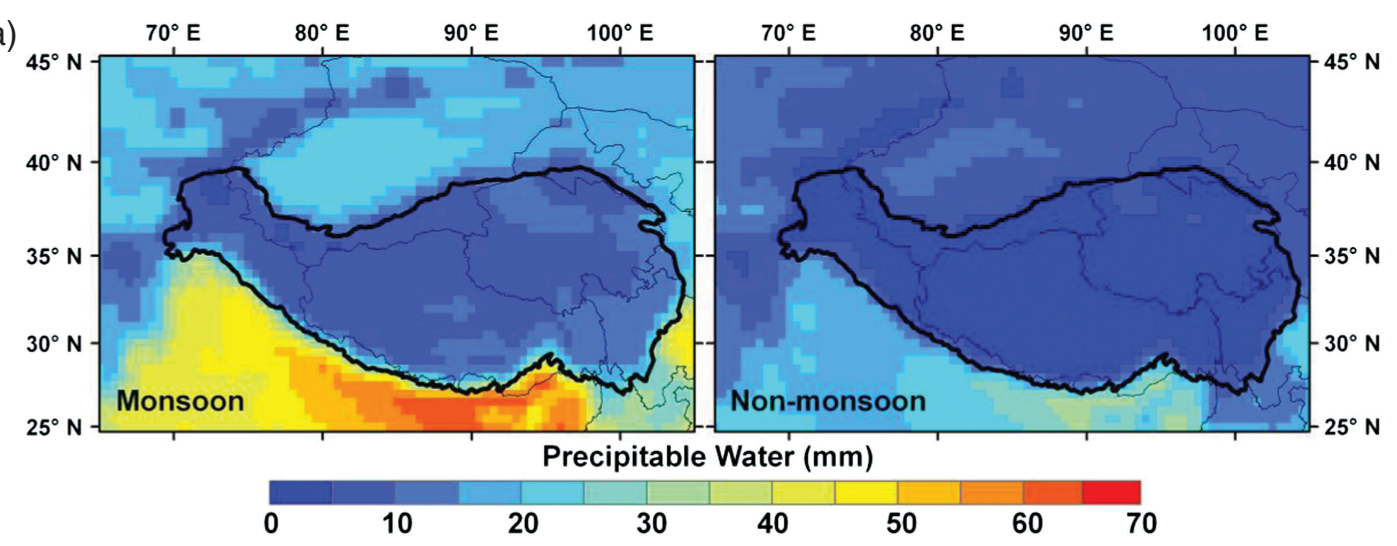

(b)

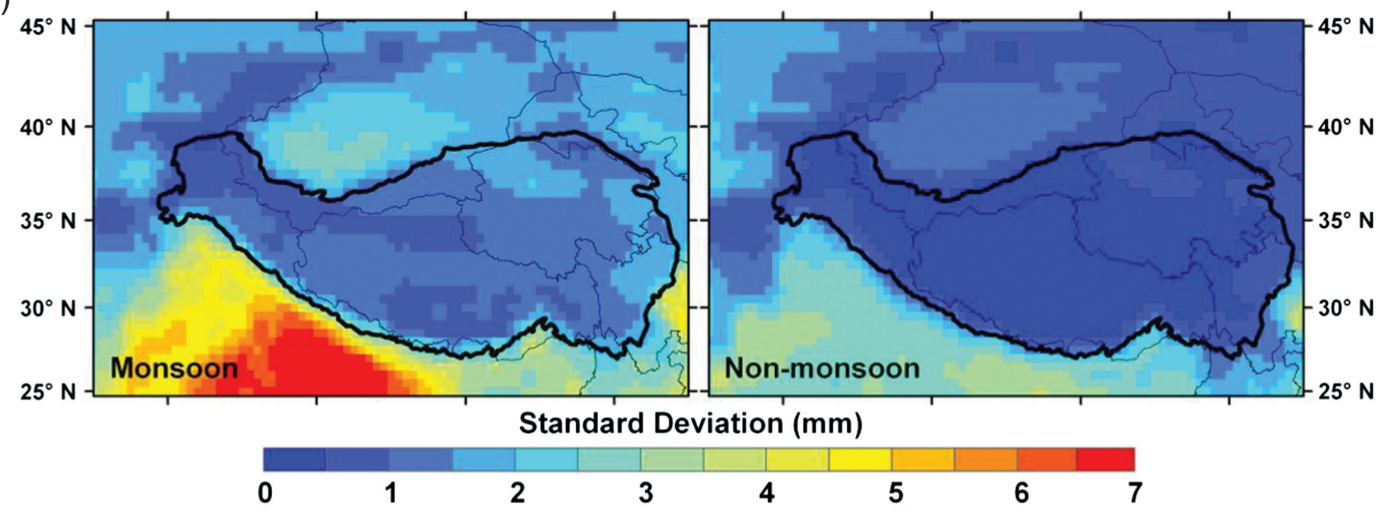

(c)

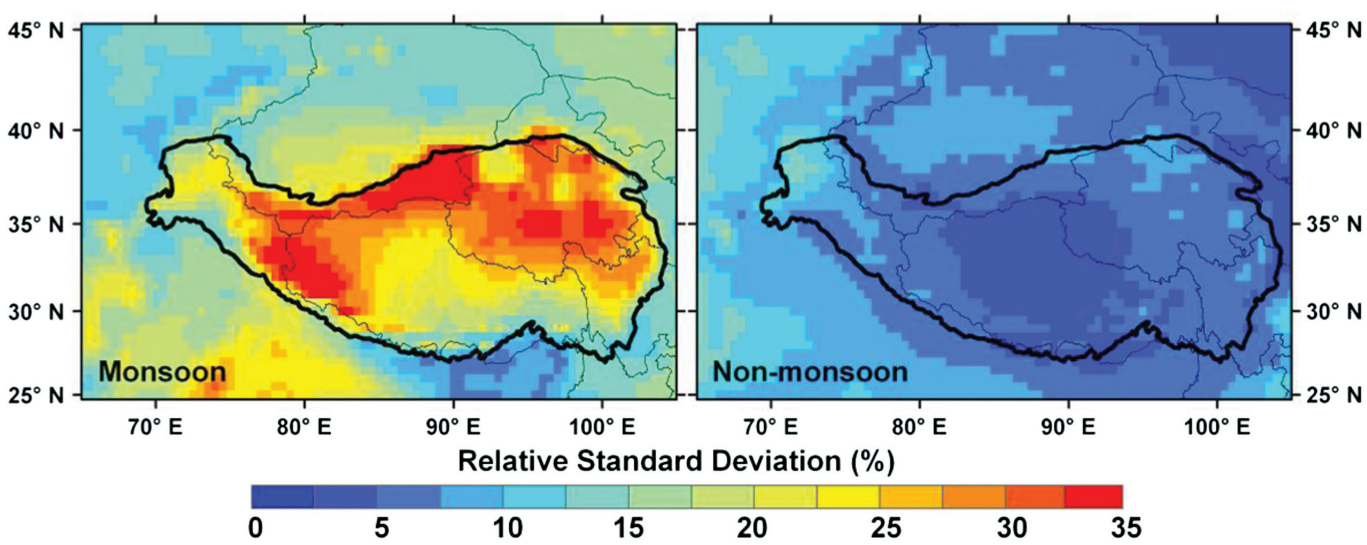

Figure 1. Means (a), standard deviations (b) and their ratios (c) of MODIS precipitable water for 2000-2010 for the monsoon and non-monsoon months. The thick line encompasses the Tibetan Plateau where elevation is above $3000 \mathrm{~m}$, and the outside areas are referred to in this study as the surrounding areas. 
The time series of monthly mean PW for 2000-2010 are illustrated in Figure 2. PW usually peaks in July and August for both the TP and the surrounding areas. The two sigmas for the PW anomalies for the TP and the surrounding areas are \pm 0.48 and $\pm 1.37 \mathrm{~mm}$, respectively. To determine the occurrence of large PW anomalies, thresholds for large PW anomalies are defined as 1 sigma. The fractional number of large anomalies found within the 11 years time series is given in Table 1. Large PW anomalies over the TP occur frequently in July and August, while for the surrounding areas they occur in June and October. The two sigmas for the PW relative anomalies for the TP and the surrounding areas are $\pm 7.37 \%$ and $\pm 5.99 \%$, respectively. It can be seen in Figure 3 that large values of the PW relative anomalies are more frequent and of larger magnitude over the TP than the surrounding areas, implying that atmospheric water vapour over the TP is more changeable compared to the surrounding areas.

The linear trend patterns of PW over the TP are determined from the time series of MODIS and ECMWF monthly mean data from 2000 to 2010, respectively. Both the absolute trends in $\mathrm{mm} / \mathrm{year}$ and relative trends in \% year $^{-1}$ are displayed (Figure 4). All the areas where the trends were not significant are hatched. A non-significant trend does not mean that the trend is wrong, but that the magnitude of the trend has a higher uncertainty (Mieruch et al., 2008).

Linear trends of MODIS PW over the TP range from -0.14 to $0.10 \mathrm{~mm} \mathrm{year}^{-1}$, and the relative linear trends from -1.25 to $1.44 \%$ year $^{-1}$. The overall areal trend is decreasing with a slope of $-0.07 \pm 0.01 \%$ year $^{-1}$ for 2000-2010. Linear trends of ECMWF PW over the TP range from -1.36 to $1.81 \%$ year $^{-1}$, with a mean areal trend of $0.09 \pm 0.03 \%$ year $^{-1}$. Although the mean areal trend for MODIS and ECMWF are different, both are small and statistically insignificant. PW trend patterns obtained from MODIS data shows that the TP can be divided into three parts: positive trends in the eastern and western TP; while negative trends appear in the middle. The trend patterns obtained from ECMWF are similar with those from MODIS except for the trends magnitude.

The mean areal trend of MODIS PW for the TP derived from SMK is $-0.06 \pm 0.01 \%$ year $^{-1}$ for 2000-2010, which is statistically insignificant because the alternative hypothesis of a two-sided test at the 95\% confidence level is rejected. The SMK trend is similar with the linear trend $\left(-0.07 \pm 0.01 \%\right.$ year $\left.^{-1}\right)$. Furthermore, the spatial pattern of trends in MODIS PW over the TP derived from SMK (Figure 5) is also similar with the pattern of linear trends. That is, SMK trends show the similar eastern-western (a)

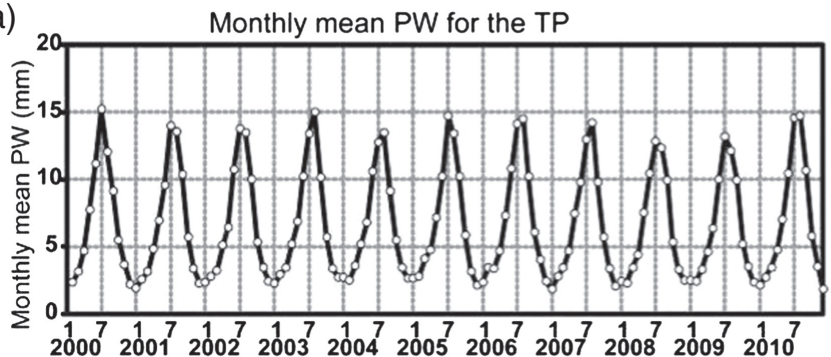

(b)

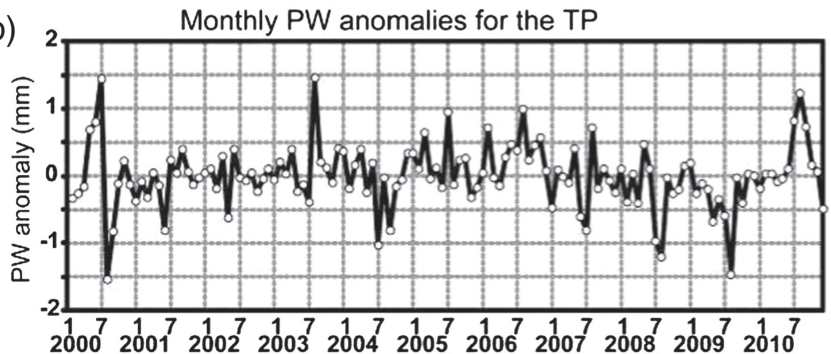

(c)

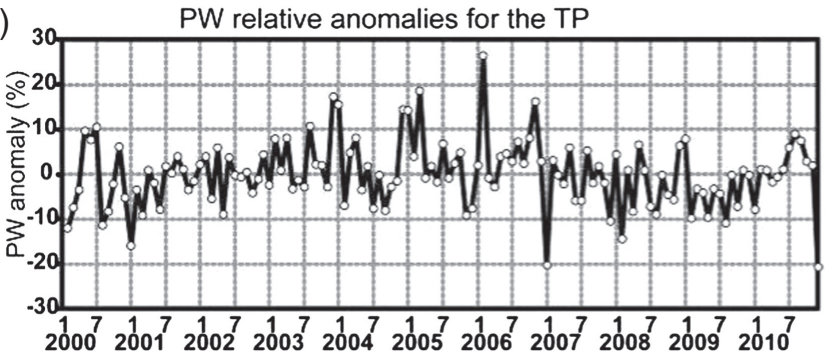

Monthly mean PW for the surrounding areas

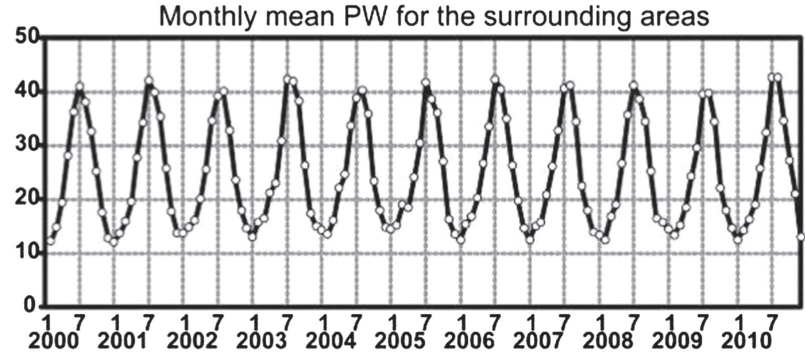

Monthly PW anomalies for the surrounding areas

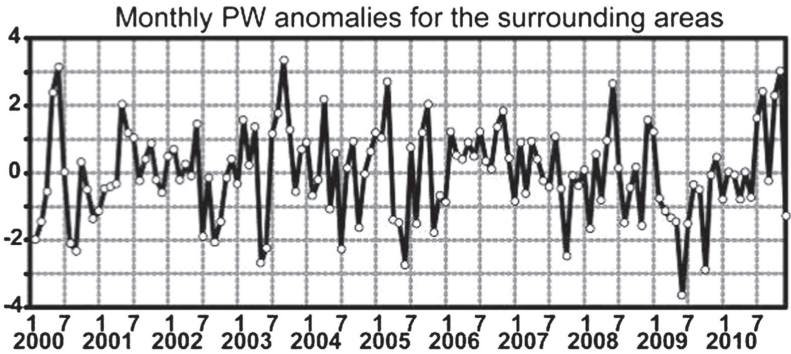

PW relative anomalies for the surrounding areas

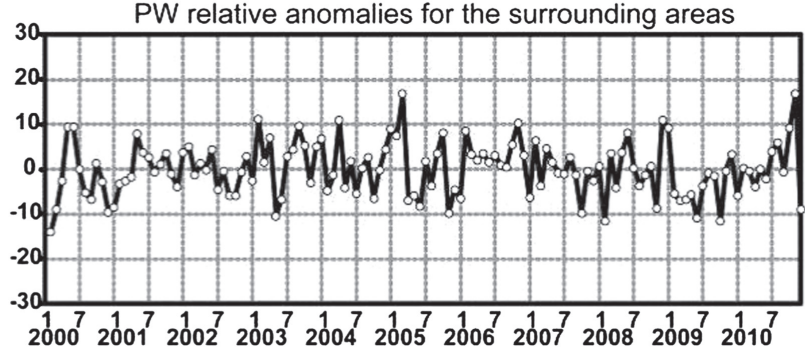

Figure 2. Time series of monthly mean (a), anomalies (b) and relative anomalies to monthly mean (c) precipitable water for 2000-2010 over the Tibetan Plateau and its surrounding areas. The relative anomaly is the ratio between absolute anomaly and PW mean over the sampling period. 
Table 1. The fractional number of large anomalies within the 11 years time series for the TP and the surrounding areas.

\begin{tabular}{|c|c|c|c|c|c|c|c|c|c|c|c|c|}
\hline & Jan. & Feb. & Mar. & Apr. & May & Jun. & Jul. & Aug. & Sep. & Oct. & Nov. & Dec. \\
\hline Tibetan Plateau & $1 / 11$ & $1 / 11$ & $1 / 11$ & $0 / 11$ & $4 / 11$ & $4 / 11$ & $7 / 11$ & $7 / 11$ & $3 / 11$ & $1 / 11$ & $1 / 11$ & $1 / 11$ \\
\hline Surrounding Areas & $0 / 11$ & $3 / 11$ & $2 / 11$ & $4 / 11$ & $5 / 11$ & $6 / 11$ & $4 / 11$ & $5 / 11$ & $3 / 11$ & $7 / 11$ & $4 / 11$ & $2 / 1$ \\
\hline
\end{tabular}

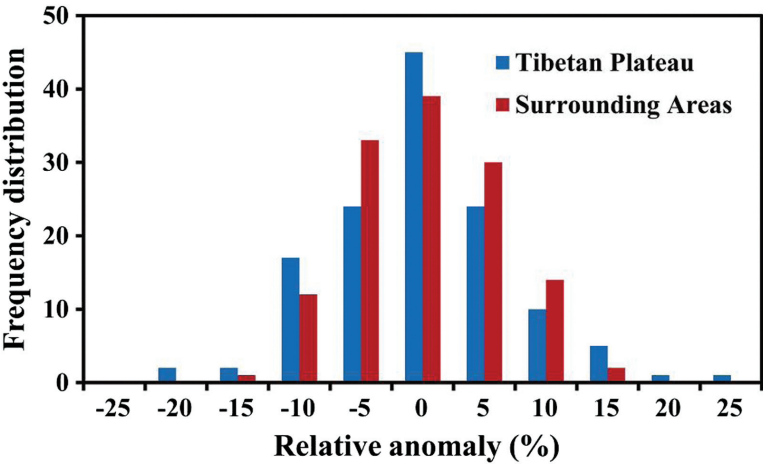

Figure 3. Frequency distributions of the PW relative anomalies for the Tibetan Plateau and the surrounding areas.

changing pattern with the linear trends for the PW over the TP.

The linear trend and SMK are designed to provide a single summary statistic for the entire record and will not indicate when there are trends in opposing directions in different time. To obtain the trend changes along with the time, EEMD method is used to get the non-linear PW trends for the TP (Figure 6). The EEMD trends show that PW trend for the TP decreases from 2000 to 2007 and then levels up. The linear slope of the EEMD trends is $-0.04 \pm 0.01$ $\%$ year $^{-1}$, which is also statistically insignificant. To better illustrate the spatial distributions of EEMD trends in PW over the TP, we calculate the EEMD trends in PW for each longitude-degree bin (from $70^{\circ} \mathrm{E}$ to $105^{\circ} \mathrm{E}$ ) over the TP. Figure 7 shows the process of PW trend changes along with the time evolution. For the eastern and western TP, the PW trends decrease first and then increase; for the middle TP, the PW trends increase first and then decrease, implying the PW changes over the TP controlled by different local mechanisms. These changes explain in part the reason why linear trends are positive in the eastern and western TP, while negative in the middle. Thus, the PW trends over the TP estimated from all three methods agree well, describing properly how PW changes over the TP.

\subsection{Effect of orbital drift on PW trend}

Orbit drift of satellite can be accounted for by assessing changes in solar zenith angle (SZA) (Gutman, 1999; Kaufmann et al., 2000). To answer whether or not a small drift in MODIS leads to spurious trends in the MODIS PW series over the TP, we use the notion of cointegration to analyse the relation between SZA and the PW data. If the SZA data contain a stochastic trend, and if this trend contaminates the PW data, then SZA will cointegrate with the PW data if the PW data do not contain a separate stochastic trend. Cointegration implies that there exists a linear combination of the variables that eliminates the stochastic trend in the data (Engle and Granger, 1987). To evaluate whether the PW data cointegrate (share a stochastic trend) with SZA, the full information likelihood procedure of Johansen Cointegration Test (Johansen and Juselius, 1990) is used to examine the relation between SZA and PW data. The procedures to estimate cointegrating vectors are derived from a vector autoregression in levels, which can be represented as:

$$
\tilde{y}_{t}=A_{1} y_{t-1}+\cdots+A_{k} y_{t-k}+\mu+\delta t+\phi d_{t}+\epsilon_{t}
$$

where $y$ is a vector of $p$ variables (i.e. PW and SZA in this case) whose behaviuor is being modelled, $k$ is the number of lags, the $A$ 's and $\phi$ are matrices of regression coefficients, $\mu$ and $\delta$ are a vector of constants, $d_{t}$ are nonintegrated exogenous variables and $\epsilon_{t}$ is a vector of error terms, each of which is normally independently and identically distributed. To test for cointegrating relations among variables in $y$ and to estimate the coefficients of the cointegrating vectors, the vector autoregression is reformulated as a vector error correction model (VECM):

$\Delta \widetilde{y}_{t}=\Gamma_{1} \Delta y_{t-1}+\cdots+\Gamma_{k-1} \Delta y_{t-k+1}+\mu+\Pi y_{t-1}+\phi \Delta d_{t}+\epsilon_{t}$

where $\Delta$ is the first difference operator. The parameters and critical values of $\lambda_{\max }$ and $\lambda_{\text {trace }}$ statistics in this VECM model are estimated by maximum likelihood to assess the relation between SZA and PW. We use no lags $(k=1)$ on the assumption that measurement errors caused by changes in SZA appear in the current measure of PW.

If there is no relation between SZA and the PW data, the $\lambda_{\max }$ and $\lambda_{\text {trace }}$ statistics will not allow us to reject the null hypothesis that there are zero cointegrating vectors. Table 2 shows the Lambda statistics of the cointegration analysis. Both the $\lambda_{\max }$ and $\lambda_{\text {trace }}$ statistics indicate that assigning a rank of zero are rejected. This allows us to reject the possibility that SZA and the MODIS PW share a stochastic trend. From this empirical analysis, we conclude that PW data from MODIS are not contaminated by trends introduced from changes in SZA due to orbital drift. As such, the MODIS PW data can be used to analyse trends and variability in atmospheric water vapour.

\subsection{Relation with surface air temperature}

To explore the effects of changing near-surface temperature on atmospheric water vapour, we have performed correlation analysis grid-by-grid between monthly mean anomalies of ECMWF surface air temperature (SAT) and MODIS PW. The large-scale correlation patterns are characteristic for monsoon and non-monsoon seasons (Figure 8). Positive correlations prevail throughout the TP, 

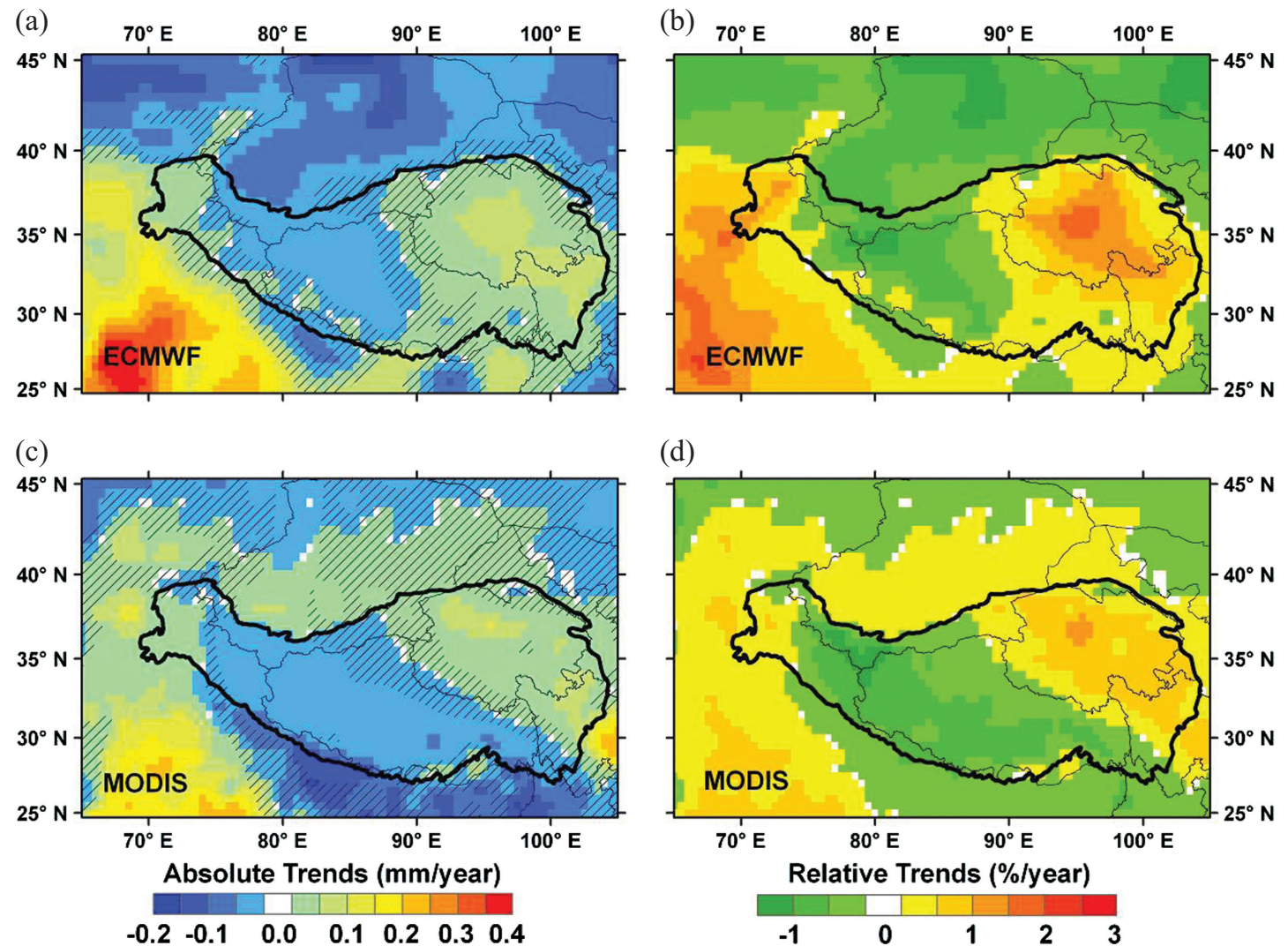

Figure 4. Absolute trends (a, c) and relative trends (b, d) in precipitable water of ECMWF and MODIS for 2000-2010 over the Tibetan Plateau. Hatched area shows that trends were not significant.
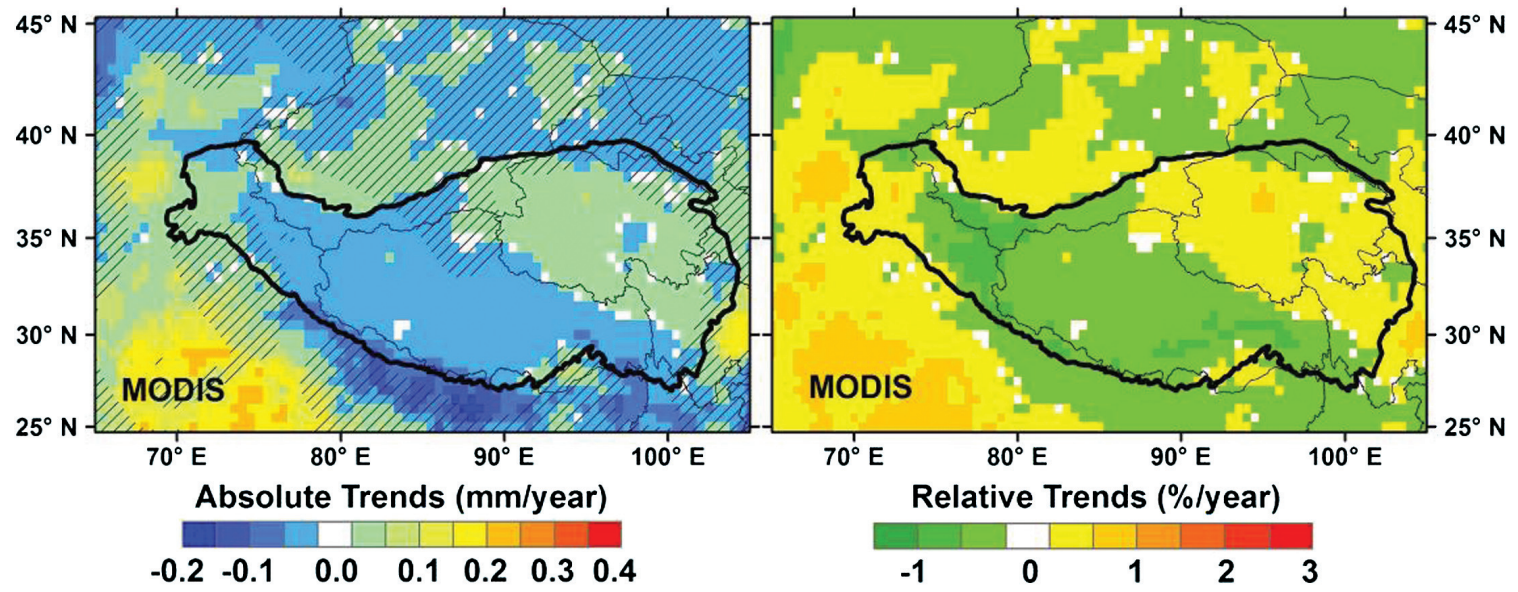

Figure 5. Same as MODIS in Figure 4, but for trends derived from seasonal Mann-Kendall method.

reflecting the increased moisture holding capacity of air with temperature. Meanwhile, weak correlations in the middle of TP where atmospheric water vapour is decreasing suggest that local temperature is not the main factor controlling the water vapour variation.

Strong negative correlations (greater than -0.5 ) occur on the southwest side of the Himalayas (mainly over the north eastern Indian subcontinent) in monsoon season, so that the atmosphere over this region in summers tend to be either hot and dry or cool and wet. In summer monsoon season, the Himalayas block moisture-laden winds flowing from the Indian Ocean, and thus large amount of water vapour is intercepted, bringing heavy rain along the entire route. Increased precipitation is reflected in more soil moisture and thus lower temperature as evaporation is enhanced. The same co-variability conditions between precipitation and surface temperature in mountain areas were found by Trenberth and Shea (2005).

For water above the oceans or on global domain, it is suggested that the Clausius-Clapeyron relation holds, whereby the water holding capacity of the atmosphere increases about $7 \% \mathrm{~K}^{-1}$ (Trenberth et al., 2003). 


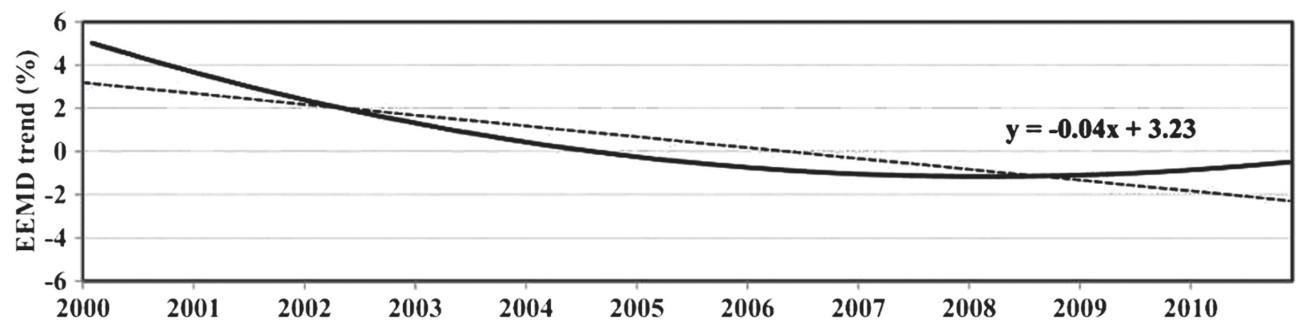

Figure 6. Non-linear trends in precipitable water calculated by the EEMD method for the whole TP.

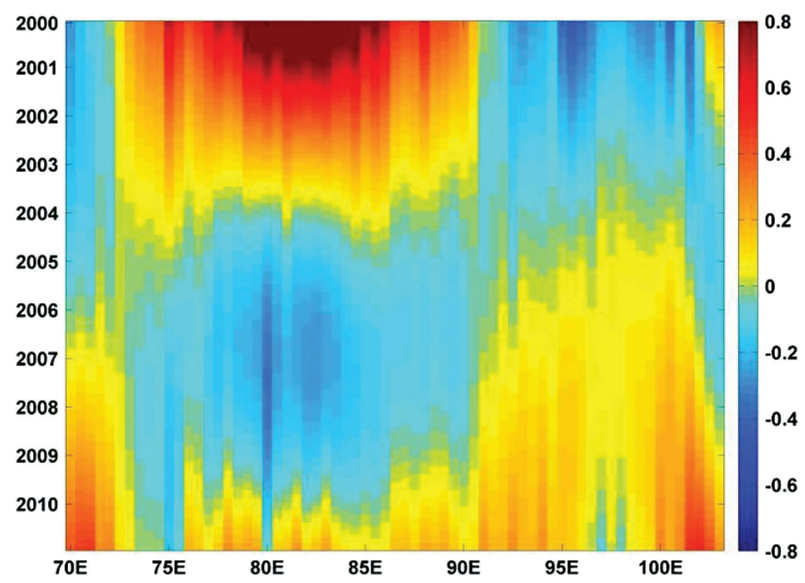

Figure 7. Evolution of EEMD trends $\left(\mathrm{mm} \mathrm{year}^{-1}\right)$ in the MODIS precipitable water from $70^{\circ} \mathrm{E}$ to $105^{\circ} \mathrm{E}$ over the $\mathrm{TP}$.

Above land, this relation is more dominated by regional non-thermodynamic effects (Sussmann et al., 2009; Vogelmann et al., 2011). For water vapour over the TP, we evaluate the strength of the water vapour-temperature feedback by regressing the monthly anomalies of PW (MODIS and ECMWF) directly against ECMWF SAT, as has been done in previous studies (Bengtsson et al., 2004; Wagner et al., 2006; Gettelman and Fu, 2008; Dessler and Davis, 2010). The same analysis was also performed over the surrounding areas for comparison. Table 3 shows the linear regression slope (absolute and relative) between PW and SAT for 2000-2010. For the TP, the ratio between MODIS PW and ECMWF SAT is less than $7 \% \mathrm{~K}^{-1}$, with $5.13 \pm 1.31 \% \mathrm{~K}^{-1}$ for monsoon season, $4.63 \pm 0.91 \% \mathrm{~K}^{-1}$ for non-monsoon season and $4.81 \pm 0.72 \% \mathrm{~K}^{-1}$ for all seasons. Nevertheless, the ratio between ECMWF PW and ECMWF SAT accords with the Clausius-Clapeyron relation, with $6.05 \pm 0.96 \% \mathrm{~K}^{-1}$ for monsoon season, $7.73 \pm 1.03 \% \mathrm{~K}^{-1}$ for non-monsoon season and $7.36 \pm 0.75 \% \mathrm{~K}^{-1}$ for all seasons. This indicates that the ratio between PW and SAT of reanalyses data over the TP is larger than that of the MODIS observations in both the monsoon and non-monsoon season. For the surrounding areas, the ratios between MODIS PW and ECMWF SAT $\left(5.21 \pm 1.53 \% \mathrm{~K}^{-1}\right.$ for monsoon season and $4.98 \pm 0.92 \% \mathrm{~K}^{-1}$ for non-monsoon season) are similar to that between ECMWF PW and ECMWF SAT $\left(4.49 \pm 1.34 \% \mathrm{~K}^{-1}\right.$ for monsoon season and $4.86 \pm 0.86$ $\% \mathrm{~K}^{-1}$ for non-monsoon season).
Table 2. Lambda statistics of the cointegration analysis.

\begin{tabular}{lccccr}
\hline$H_{0}^{*}$ & \multicolumn{2}{c}{ Critical value } & & \multicolumn{2}{c}{ VECM model } \\
\cline { 2 - 3 } \cline { 6 - 6 } & $\lambda_{\max }$ & $\lambda_{\text {trace }}$ & & $\lambda_{\max }$ & $\lambda_{\text {trace }}$ \\
\hline 0 & 14.26 & 15.4948 & & $\mathbf{7 0 . 5 2}$ & $\mathbf{1 0 5 . 5 1}$ \\
1 & 3.84 & 3.84 & & $\mathbf{3 4 . 9 8}$ & $\mathbf{3 4 . 9 8}$ \\
\hline
\end{tabular}

$* H_{0}$ stands for null hypothesis for the number of cointegrating relations.

\subsection{Influence of water vapour transport}

If we only take into consideration the Clausius-Clapeyron relation of increasing $\mathrm{PW}$ with surface temperature, the overall temperature increase across the TP (Qin et al., 2009) would lead to coherent increasing patterns of PW, not the distinctive trend characteristics we obtained in Section 3.1 The PW variability over the TP is not only caused by the local temperature changes, but also influenced by the water vapour transport from the surrounding areas which is controlled by large-scale circulation (Chen et al., 2012). Figure 9 shows the linear trends in the vertically integrated moisture flux (Figure 9(a)) and their divergence (Figure 9(b)) over the TP derived from ERA-Interim reanalysis during 2000-2010. The spatial pattern of the trends in flux divergence of water vapour (Figure 9(b)) matches well with the PW trends over the TP: the water vapour converges in the eastern and western TP, while diverges in the middle. Meanwhile, the water vapour flux transported to the Pacific increases (Figure 9(a)), which is consistent with the finding of acceleration in Pacific winds (England et al., 2014).

We further derived the PW relative trend (in $\%$ year $^{-1}$ ) patterns for the monsoon and non-monsoon seasons, respectively (Figure 10). From comparison of Figure 4(d) with Figure 10(a) it is obvious that the PW trends over the TP are mainly determined by the PW trend during monsoon seasons because it shows the similar patterns to that of annual mean. The PW monthly anomalies for 2000-2010 (Figure 2) were averaged for monsoon months (May, June, July, August, September) in each year to identify the wet and dry monsoon seasons on the TP. It is found that the monsoon season in 2008 is the driest (with the anomaly of $-0.69 \mathrm{~mm}$ ) and the monsoon season in 2010 is the wettest (with the anomaly of 0.71 $\mathrm{mm}$ ). Therefore, the vertically integrated moisture flux and their divergence derived from ERA-Interim reanalysis data were compared for these two monsoon seasons to show the pathways of water vapour transport to the TP 


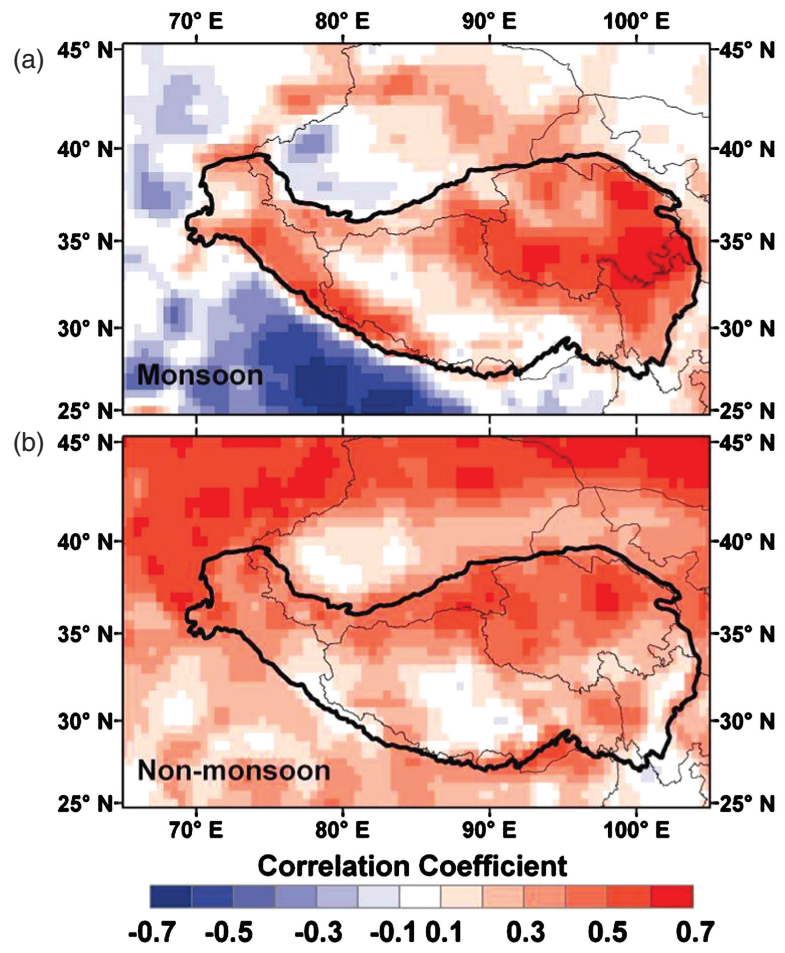

Figure 8. Correlation between monthly mean anomalies of ECMWF surface air temperature and MODIS precipitable water for monsoon (a) and non-monsoon (b) seasons for 2000-2010.

(Figure 11). In the wet monsoon season (Figure 11(a)), the strong southwesterly circulation (i.e. the Indian monsoon) brings moisture from the Arabian Sea, the Bay of Bengal and southern Indian Ocean to the TP, as found by many previous studies (Simmonds et al., 1999; Xu et al., 2008a; Drumond et al., 2011; Chen et al., 2012; Yao et al., 2013). However, Sun and Wang (2014) have recently found through Lagrangian particle dispersion model simulation that the major moisture sources for the eastern TP are the continental areas, including local TP domains and northwestern China-eastern Central Asia, although they recognized that there is also a respectable amount of moisture taken from the Indian Ocean. As the moisture is transported from the Bay of Bengal to the south flank of the TP, it is captured by the Himalayas. As a result, a large portion of it converges to east side of the mountain range. Moreover, the other portion of water

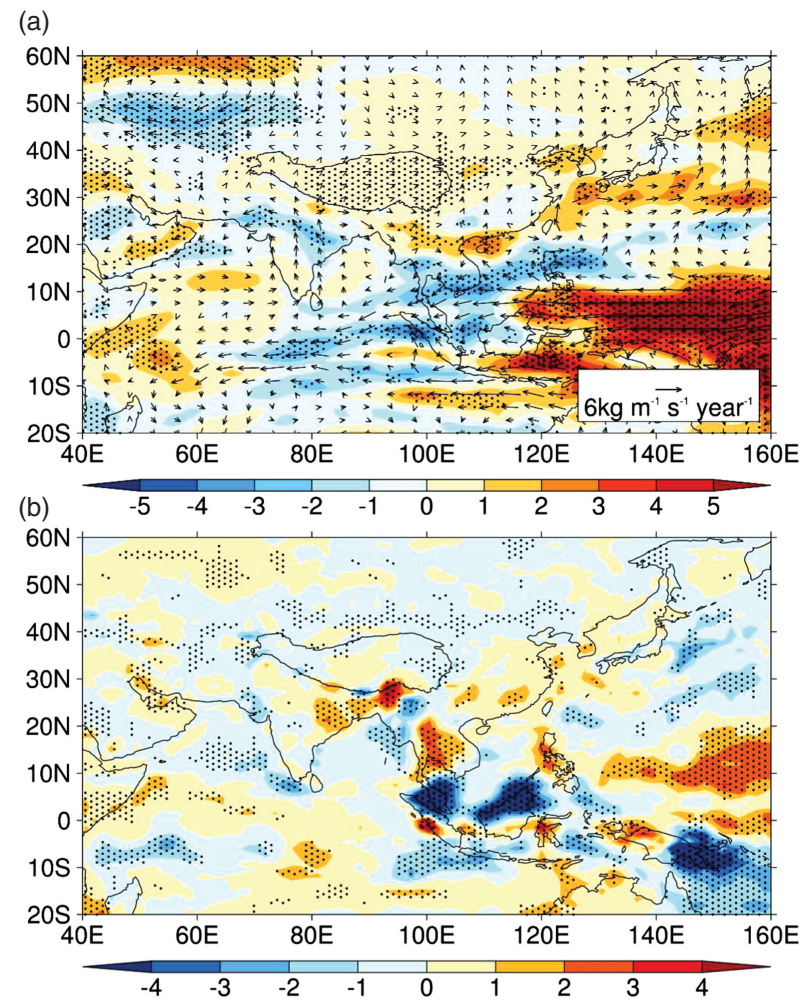

Figure 9. Linear trends in water vapour flux (colour shading, $\mathrm{kg} \mathrm{m}^{-1} \mathrm{~s}^{-1}$ year $^{-1}$ ) with vectors (a) and trends in flux divergence of water vapour (colour shading, $10^{-5} \mathrm{~kg} \mathrm{~m}^{-2} \mathrm{~s}^{-1}$ year $^{-1}$ ) (b) for 2000-2010. In all panels, stippling indicates where the trends are significant at the $95 \%$ confidence level over the entire period. Refer to Figure S1 for the details over the TP.

vapour is deflected along the west side of the Himalayas, which causes moisture convergence through the mountain range.

Meanwhile, it should be noted that there is a very strong anticyclone (i.e. the southeastern Asian monsoon) along the west margin of the western Pacific. Xu et al. (2008b) suggested that the eastward moisture transport from the Bay of Bengal and the westward transport from the Philippine Islands converge over South China Sea, and then turn northeastward into southeastern China. In the dry monsoon season (Figure 11(b)), as the anticyclone centre in the western Pacific moves northwestwards, the water vapour flux transported to the Eastern TP and the west side of the Himalayas decreases. The convergence of the

Table 3. Slope in linear regression fit of precipitable water on surface air temperature for 2000-2010.

\begin{tabular}{|c|c|c|c|c|}
\hline & \multicolumn{2}{|c|}{ Tibetan Plateau } & \multicolumn{2}{|c|}{ Surrounding areas } \\
\hline & $\begin{array}{c}\text { MODIS/SAT } \\
\mathrm{mm} \mathrm{K}^{-1} *\left(\% \mathrm{~K}^{-1}\right)\end{array}$ & $\begin{array}{c}\text { ECMWF/SAT } \\
\mathrm{mm} \mathrm{K}^{-1}\left(\% \mathrm{~K}^{-1}\right)\end{array}$ & $\begin{array}{c}\text { MODIS/SAT } \\
\mathrm{mm} \mathrm{K}^{-1}\left(\% \mathrm{~K}^{-1}\right)\end{array}$ & $\begin{array}{c}\text { ECMWF/SAT } \\
\mathrm{mm} \mathrm{K}^{-1}\left(\% \mathrm{~K}^{-1}\right)\end{array}$ \\
\hline Monsoon & $\begin{array}{c}0.56 \pm 0.14 \\
(5.13 \pm 1.31)\end{array}$ & $\begin{array}{c}0.54 \pm 0.10 \\
(6.05 \pm 0.96)\end{array}$ & $\begin{array}{c}1.09 \pm 0.42 \\
(5.21 \pm 1.53)\end{array}$ & $\begin{array}{c}0.84 \pm 0.33 \\
(4.49 \pm 1.34)\end{array}$ \\
\hline Non-monsoon & $\begin{array}{c}0.12 \pm 0.02 \\
(4.63 \pm 0.91)\end{array}$ & $\begin{array}{c}0.15 \pm 0.02 \\
(7.73 \pm 1.03)\end{array}$ & $\begin{array}{c}0.51 \pm 0.10 \\
(4.98 \pm 0.92)\end{array}$ & $\begin{array}{c}0.45 \pm 0.08 \\
(4.86 \pm 0.86)\end{array}$ \\
\hline All seasons & $\begin{array}{c}0.21 \pm 0.05 \\
(4.81 \pm 0.72)\end{array}$ & $\begin{array}{c}0.23 \pm 0.04 \\
(7.36 \pm 0.75)\end{array}$ & $\begin{array}{c}0.58 \pm 0.11 \\
(5.01 \pm 0.73)\end{array}$ & $\begin{array}{c}0.49 \pm 0.09 \\
(4.81 \pm 0.68)\end{array}$ \\
\hline
\end{tabular}

*The value after ' \pm ' is the two-sigma uncertainty. 


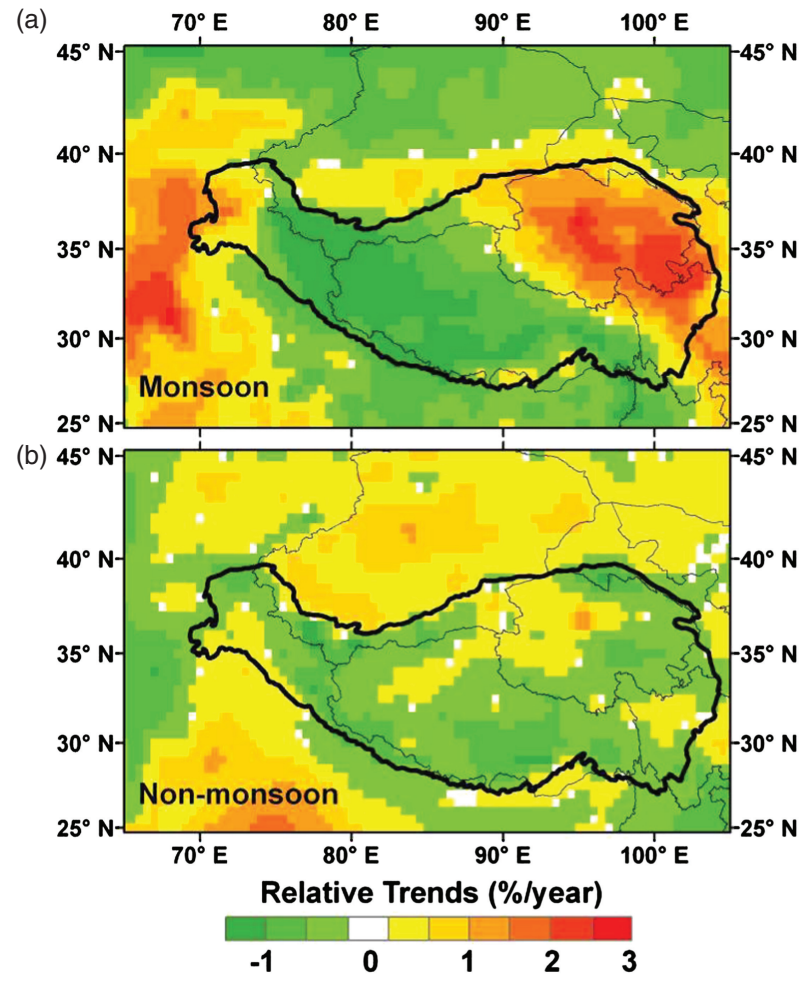

Figure 10. Relative trends (in $\%$ year $^{-1}$ ) in MODIS precipitable water for monsoon (a) and non-monsoon (b) seasons over the Tibetan Plateau.

water vapour along the east side of the mountain range expands southward. The difference of the vertically integrated moisture flux between the wet and dry monsoon season (Figure 11(c)) illustrates that more water vapour from the Indian Ocean is carried to pass through Southeast Asia and into the South China Sea in the dry monsoon season. Meanwhile, the water vapour convergence over the Eastern TP is lessened in the dry monsoon season as compared to the wet monsoon season. The change pattern may suggest that the PW spatial variability in monsoon seasons over the TP is affected by large-scale circulation in such a way that as the anticyclone centre in the western Pacific moves northwestwards, the water vapour transported from the Indian Ocean to the TP decreases and that to the South China Sea increases.

\section{Conclusions}

This study presents the PW trends and variability over the TP for 2000-2010. First, the statistically significant trends were estimated from monthly mean PW datasets of MODIS and ECMWF by using three different methods. The trend detection was performed grid-by-grid on the MODIS and ECMWF data to obtain the trend patterns of the TP. Second, the correlation between water vapour and temperature over the TP and the surrounding areas were discussed, respectively. Third, the vertically integrated moisture flux and their divergence were compared to demonstrate water vapour transport to the TP.
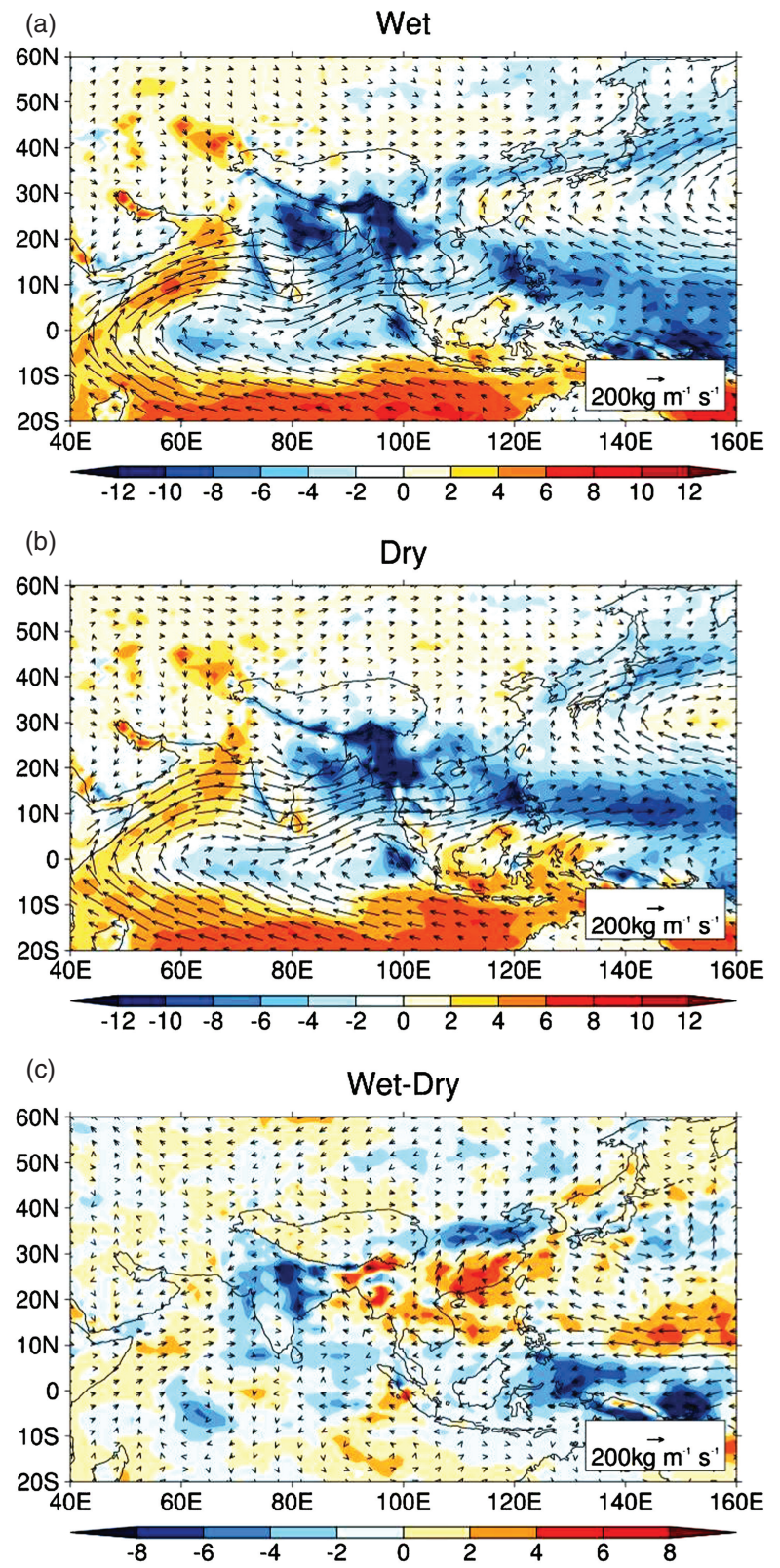

Figure 11. Seasonal mean vertically integrated moisture flux (vector, $\mathrm{kg}$ $\mathrm{m}^{-1} \mathrm{~s}^{-1}$ ) and divergence (contour shades, $10^{-5} \mathrm{~kg} \mathrm{~m}^{-2} \mathrm{~s}^{-1}$ ) for TP wet monsoon season in 2010 (a), dry monsoon season (b) in 2008, and their difference (c). Refer to Figure S2 for the details over the TP.

The trend patterns derived from MODIS are similar with those from ECMWF except for the trends magnitude. Moreover, all three methods of trend estimation from MODIS give similar spatial patterns. It turns out that the PW trend patterns on the TP are distinctive: positive trends in eastern and western TP; while decreasing trends in the middle. Trends of PW over the TP and its surrounding area are spatially heterogeneous, even though the region is under the influence of large-scale circulation pattern commonly referred to as the monsoon. After the check for the monsoon and non-monsoon seasons, we find that the PW trends above the TP are dominated by the PW variability in monsoon seasons. This fact is particularly important for predicting hydrological changes in the region because 
there is a significantly positive correlation between variability and predictability (Sun and Wang, 2012).

Regression analysis between monthly mean anomalies of MODIS PW and ECMWF SAT for the TP shows that the ratios between MODIS PW and ECMWF SAT are less than $7 \% \mathrm{~K}^{-1}$, whereas the ratios between ECMWF PW and ECMWF SAT accord with the Clausius-Clapeyron relation, indicating reanalyses data hold stronger local relationships over the TP than the observations in both the monsoon and non-monsoon season. For the surrounding areas, however, the ratios between MODIS PW and ECMWF SAT are similar to that between ECMWF PW and ECMWF SAT, with the ratios generally below $7 \%$ $\mathrm{K}^{-1}$. Those findings can be used in climate model studies for the TP region to test hypotheses about the relationship between water vapour and temperature.

The comparison of the vertically integrated moisture flux and their divergence between the wet monsoon season and dry monsoon season on the TP highlights details of water vapour transport. It adds evidence to the current understanding that the PW spatial variability in monsoon seasons over the TP is affected by large-scale circulation, especially movements of the anticyclone along the west margin of the western Pacific. Composite analysis with long-term datasets should be made in the future to figure out to what extent this large-scale pattern plays a role in influencing the atmospheric water vapour over the whole region.

\section{Acknowledgements}

This study was supported by the National Natural Science Foundation of China (grants 41371016 and 41001215), the Youth Science Funds of LREIS, CAS and the Youth Innovation Promotion Association, CAS.

\section{Supporting Information}

The following supporting information is available as part of the online article:

Figure S1. Same as Figure 9, but for a narrower view area for the TP with small colour scales.

Figure S2. Same as Figure 11, but for a narrower view area for the TP with small colour scales.

\section{References}

Bengtsson L, Hagemann S, Hodges KI. 2004. Can climate trends be calculated from reanalysis data? J. Geophys. Res. 109: D11111, DOI: 10.1029/2004JD004536.

Boos WR, Kuang Z. 2010. Dominant control of the South Asian monsoon by orographic insulation versus plateau heating. Nature 463 : 218-222, DOI: 10.1038/nature08707.

Chen B, Xu X, Yang S, Zhang W. 2012. On the origin and destination of atmospheric moisture and air mass over the Tibetan Plateau. Theor Appl. Climatol. 110(3): 423-435, DOI: 10.1007/s00704-012-0641-y.

Dee DP, Uppala SM. 2009. Variational bias correction of satellite radiance data in the ERA-Interim reanalysis. Q. J. R. Meteorol. Soc. 135 : $1830-1841$.

Dee DP, Uppala SM, Simmons AJ, Berrisford P, Polia P, Kobayashi S, Andraec U, Balmaseda MA, Balsamo G, Bauer P, Bechtold P, Beljaars
ACM, van de Berg L, Bidlot J, Bormann N, Delsol C, Dragani R, Fuentes M, Geer AJ, Haimberger L, Healy SB, Hersbach H, Hólm EV, Isaksen L, Kållberg P, Köhler M, Matricardi M, McNally AP, Monge-Sanz BM, Morcrette J-J, Park B-K, Peubey C, de Rosnay P, Tavolato C, Thépaut J-N, Vitart F. 2011. The ERA-Interim reanalysis: configuration and performance of the data assimilation system. $Q . J$. R. Meteorol. Soc. 137: 553-597.

Dessler AE, Davis SM. 2010. Trends in tropospheric humidity from reanalysis systems. J. Geophys. Res. 115: D19127, DOI: 10.1029/2010JD014192.

Dessler AE, Zhang Z, Yang P. 2008. Water-vapor climate feedback inferred from climate fluctuations, 2003-2008. Geophys. Res. Lett. 35: L20704, DOI: 10.1029/2008GL035333.

Drumond A, Nieto R, Gimeno L. 2011. Sources of moisture for China and their variations during drier and wetter conditions in 2000-2004: a Lagrangian approach. Clim. Res. 50: 215-225.

England MH, McGregor S, Spence P, Meehl GA, Timmermann A, Cai W, Gupta AS, McPhaden MJ, Purich A, Santoso A. 2014. Recent intensification of wind-driven circulation in the Pacific and the ongoing warming hiatus. Nature Clim. Change 4: 222-227.

Engle RE, Granger WJ. 1987. Cointegration and error-correction: Representation, estimation and testing. Econometrica 55: 251-276.

Gao BC, Kaufman YJ. 2003. Water vapor retrievals using Moderate Resolution Imaging Spectroradiometer (MODIS) near-infrared channels. J. Geophys. Res. 108(D13): 4389, DOI: 10.1029/2002JD003023.

Gao BC, Yang P, Guo G, Park SK, Wiscombe WJ, Chen B. 2003. Measurements of water vapor and high clouds over the Tibetan Plateau with the Terra MODIS instrument. IEEE Trans. Geosci. Remote Sens. 41(4): 895-900.

Gettelman A, Fu Q. 2008. Observed and simulated upper-tropospheric water vapor feedback, J. Clim., 21, 3282-3289, DOI: 10.1175/ 2007JCLI2142.1.

Gutman GG. 1999. On the monitoring of land surface temperatures with the NOAA/AVHRR: removing the effect of satellite orbit drift. Int. J. Remote Sens. 20: 3407-3413.

Hirsch RM, Slack JR. 1984. A nonparametric trend test for seasonal data with serial dependence. Water Resour. Res. 20: 727-732.

Johansen S, Juselius K. 1990. Maximum likelihood estimation and inference on cointegration with application to the demand for money. Oxford Bull. Econ. Stat. 52: 169-209.

Kaufmann RK, Zhou L, Knyazikhin Y, Shabanov NV, Myneni RB, Tucker CJ. 2000. Effect of orbital drift and sensor changes on the time series of AVHRR vegetation index data. IEEE Trans. Geosci. Remote Sens. 38: 2584-2597.

Lu N, Qin J, Yang K, Gao Y, Xu X, Koike T. 2011. On the use of GPS measurements for Moderate Resolution Imaging Spectrometer precipitable water vapor evaluation over southern Tibet. J. Geophys. Res. 116: D23117, DOI: 10.1029/2011JD016160.

Mieruch S, Noël S, Bovensmann H, Burrows JP. 2008. Analysis of global water vapour trends from satellite measurements in the visible spectral range. Atmos. Chem. Phys. 8: 491-504, DOI: 10.5194/acp-8-491-2008.

Qin J, Yang K, Liang S, Guo X. 2009. The altitudinal dependence of recent rapid warming over the Tibetan Plateau. Clim. Change 97: 321-327, DOI: 10.1007/s10584-009-9733-9.

Simmonds I, Bi D, Hope P. 1999. Atmospheric water vapor flux and its association with rainfall over China in summer. J. Clim. 12: $1353-1367$.

Sun B, Wang H. 2012. Larger variability, better predictability? Int. J. Climatol. 33: 2341-2351.

Sun B, Wang H. 2014. Moisture sources of semiarid grassland in China using the Lagrangian particle model FLEXPART. J. Clim. 27: 2457-2474.

Sussmann R, Borsdorff T, Rettinger M, Camy-Peyret C, Demoulin P, Duchatelet P, Mahieu E, Servais C. 2009. Technical note: harmonized retrieval of column-integrated atmospheric water vapor from the FTIR network - first examples for long-term records and station trends. Atmos. Chem. Phys. 9: 8987-8999, DOI: 10.5194/acp-9-8987-2009.

Tang H, Micheels A, Eronen JT, Ahrens B, Fortelius M. 2013. Asynchronous responses of East Asian and Indian summer monsoons to mountain uplift shown by regional climate modeling experiments. Clim. Dyn. 40: 1531-1549.

Trenberth KE, Shea DJ. 2005. Relationships between precipitation and surface temperature. Geophys. Res. Lett. 32: L14703, DOI: 10.1029/2005GL022760.

Trenberth KE, Dai A, Rasmussen RM, Parsons DB. 2003. The changing character of precipitation. Bull. Am. Meteorol. Soc. 84: 1205-1217. 
Trenberth KE, Fasullo J, Smith L. 2005. Trends and variability in column-integrated atmospheric water vapor. Clim. Dyn. 24: $741-758$

Vogelmann H, Sussmann R, Trickl T, Borsdorff T. 2011. Intercomparison of atmospheric water vapor soundings from the differential absorption lidar (DIAL) and the solar FTIR system on Mt. Zugspitze. Atmos. Meas. Tech. 4: 835-841.

Wagner T, Beirle S, Grzegorski M, Platt U. 2006. Global trends (1996-2003) of total column precipitable water observed by Global Ozone Monitoring Experiment (GOME) on ERS-2 and their relation to near-surface temperature. J. Geophys. Res. 111: D12102, DOI: 10.1029/2005JD006523.

Weatherhead EC, Reinsel GC, Tiao GC, Meng XL, Choi D, Cheang WK, Keller T, DeLuisi J, Wuebbles DJ, Kerr JB, Miller AJ, Oltmans SJ, Frederick JE. 1998. Factors affecting the detection of trends: Statistical considerations and applications to environmental data. J. Geophys. Res. 103(D14): 17149-17161, DOI: 10.1029/ 98JD00995.

Wu Z, Huang NE. 2009. Ensemble empirical mode decomposition: a noise-assisted data analysis method. Adv. Adapt. Data Anal. 1: 1-41.

Wu G, Liu Y, He B, Bao Q, Duan A, Jin FF. 2012. Thermal controls on the Asian summer monsoon. Sci. Rep. 2: 404, DOI: $10.1038 /$ srep00404.
Xu X, Lu C, Shi X, Gao S. 2008a. World water tower: An atmospheric perspective. Geophys. Res. Lett. 35: L20815, DOI: 10.1029/2008GL035867.

Xu X, Shi X, Wang Y, Peng S, Shi X. 2008b. Data analysis and numerical simulation of moisture source and transport associated with summer precipitation in the Yangtze River Valley over China. Meteorol. Atmos. Phys. 100(1): 217-231, DOI: 10.1007/s00703-008-0305-8.

Yanai M, Wu G. 2006. Effects of the Tibetan Plateau. In The Asian Monsoon, Wang B (ed). Praxis: Chichester, UK, 513-549.

Yang K, Koike T, Fujii H, Tamura T, Xu X, Bian L, Zhou M. 2004. The daytime evolution of the atmospheric boundary layer and convection over the Tibetan Plateau: observations and simulations. J. Meteorol. Soc. Jpn. 82: 1777-1792.

Yang K, Ding B, Qin J, Tang W, Lu N, Lin C. 2012. Can aerosol loading explain the solar dimming over the Tibetan Plateau? Geophys. Res. Lett. 39: L20710, DOI: 10.1029/2012GL053733.

Yao T, Delmotte VM, Gao J, Yu W, Yang X, Risi C, Sturm C, Werner M, Zhao H, He Y, Ren W, Tian L, Shi C, Hou S. 2013. A review of climatic controls on $\delta 18 \mathrm{O}$ in precipitation over the Tibetan Plateau: observations and simulations. Rev. Geophys. 51: 525-548.

Zhang R. 2001. Relations of water vapor transport from Indian monsoon with that over East Asia and the summer rainfall in China. Adv. Atmos. Sci. 18(5): 1005-1017. 